Bul. Agrohorti 3 (2) : 245 - 251 (2015)

\title{
Kualitas Visual dan Fungsional Turfgrass pada Beberapa Waktu Awal dan Frekuensi Aplikasi Pupuk Hayati
}

\author{
Visual and Functional Quality of Turfgrass on Several First Application Times and Frequencies of \\ Biofertilizer Application
}

\author{
Yusak, Dwi Guntoro*, dan Achmad Zakaria
}

Departemen Agronomi dan Hortikultura, Fakultas Pertanian, Institut Pertanian Bogor

(Bogor Agricultural University), Jl. Meranti, Kampus IPB Darmaga, Bogor 16680, Indonesia

Telp.\& Faks.62-251-8629353 e-mail agronipb@indo.net.id

*Penulis untuk korespondensi: dwiguntoro@yahoo.com

Disetujui 7 Mei 2015 / Published online 15 Mei 2015

\begin{abstract}
Inorganic fertilization with relatively high dosage and frequency is mostly done to maintain quality, density and uniformity of turfgrass. However this practice has caused soil and water pollution. Using biofertilizer was done to reduce the use of inorganic fertilizers. The objective of the research was to study the visual and functional quality of turfgrass on several first application times and frequencies of biofertilizer application. This research was done in Bukit Pelangi Golf Course, Cijayanti, Bogor from February until August 2012. The experiment was arranged at split plots in randomized block design with 2 factors, which are: first application times and frequencies of biofertilizer application, in 4 replications. First application times as the main plot consist of 4 levels, which are: 1, 2, 3, and 4 weeks before planting. Frequencies of biofertilizer application as the sub-plot consists of four levels, which are: once every 1, 2, 3, and 4 weeks. The results showed that application frequency at once a week showed the best visual and functional quality and not significantly different compared to the frequency of application at once every two weeks. First application time at three weeks before planting and the frequency of application at once every two weeks was the best treatment to enhance the visual and functional turfgrass quality, which increase shoot density, leaf width, leaf color, leaf length, biomass clipping, the percentage of couverage, root length, root biomass, increased the recovery, and decreased the diameter of stolon.
\end{abstract}

Keywords: Cynodon dactylon (L.), first application, frequencies, tifdwarft, turfgrass

ABSTRAK

Pemberian pupuk anorganik dengan dosis dan frekuensi yang relatif tinggi banyak dilakukan untuk mempertahankan kualitas, densitas, dan keseragaman rumput golf, tetapi dapat mengakibatkan pencemaran tanah dan perairan. Penggunaan pupuk hayati diharapkan dapat mengurangi penggunaan pupuk anorganik. Penelitian bertujuan untuk mempelajari pengaruh waktu awal dan frekuensi aplikasi pupuk hayati terhadap kualitas visual dan fungsional turfgrass. Penelitian dilaksanakan di lapangan Golf Bukit Pelangi, Cijayanti, Bogor mulai bulan Februari sampai Agustus 2012. Percobaan menggunakan Rancangan Split Plot dalam RKLT dengan 2 faktor yaitu waktu awal aplikasi dan frekuensi aplikasi pupuk hayati dengan 4 ulangan. Waktu awal aplikasi sebagai petak utama terdiri atas empat taraf, yaitu 1, 2, 3, dan 4 minggu sebelum tanam. Frekuensi aplikasi pupuk hayati sebagai anak petak terdiri atas 4 taraf, yaitu frekuensi 1, 2, 3 dan 4 minggu sekali. Hasil percobaan menunjukkan bahwa frekuensi aplikasi satu minggu sekali menunjukkan kualitas visual dan fungsional terbaik dan tidak berbeda nyata dibandingkan frekuensi aplikasi dua minggu sekali. Waktu awal aplikasi tiga minggu sebelum tanam dan frekuensi aplikasi dua minggu sekali merupakan perlakuan terbaik untuk mempertahankan kualitas visual dan fungsional turfgrass, yaitu meningkatkan kepadatan pucuk, lebar daun, warna daun, panjang daun, biomassa pangkasan, persentase penutupan tajuk, meningkatkan panjang akar, biomassa akar, mempercepat waktu recovery, dan menurunkan diameter stolon.

Kata kunci : awal aplikasi, Cynodon dactylon (L.), frequensi, Tifdwarft, turfgrass 


\section{PENDAHULUAN}

Turfgrass merupakan tanaman ornamental penutup tanah (ground cover) berupa rumput yang banyak digunakan sebagai sarana olahraga seperti golf, sepak bola, base ball, dan banyak lagi kegiatan olah raga lainnya (Emmons, 2000). Jenis turfgrass yang banyak digunakan di daerah tropis berupa rumput Bermuda (Cynodon dactylon (L.) Pers.), Zoysia matrella, dan Axonopus compressus. Rumput Bermuda (Cynodon dactylon (L.) var. Tifdwarft) merupakan jenis turfgrass yang paling banyak digunakan. Jenis tersebut memiliki kelebihan yaitu tumbuh menjalar, berdaun dan berbatang kecil, kanopi kompak, tahan kekeringan, dan mampu tumbuh baik dengan pemotongan rendah (Turgeon, 2004). Rumput Bermuda juga tahan cekaman salin dan $\mathrm{pH}$ rendah (Schaan et al., 2003).

Pemberian pupuk anorganik dengan dosis dan frekuensi yang relatif tinggi banyak dilakukan untuk mempertahankan kualitas, densitas, dan keseragaman rumput golf (Guntoro, 2007). Pemupukan pada green area per tahun di lapangan golf membutuhkan nitrogen, phosfor, dan kalium masing masing 12-16 lbs/1000 $\mathrm{ft}^{2}, 1 \mathrm{lbs} / 1000 \mathrm{ft}^{2}$, dan $1 \mathrm{lbs} / 1000 \mathrm{ft}^{2}$ (Emmons, 2000). Pemupukan dengan dosis dan frekuensi yang relatif tinggi di lapangan golf mengakibatkan pencemaran tanah dan perairan sekitar akibat pencucian pupuk. Tindakan pengelolaan turfgrass saat ini lebih banyak dilakukan untuk mengurangi penggunaan pupuk anorganik dengan aplikasi pupuk hayati.

Pupuk hayati adalah produk biologi aktif terdiri dari mikroba yang dapat meningkatkan efisiensi pemupukan, kesuburan, dan kesehatan tanah (Permentan, 2009). Mikroorganisme ini ada yang hidup dengan cara bersimbiosis dan ada juga yang hidup di sekitar akar rumput golf. Beberapa organisme yang temasuk dalam golongan pupuk hayati adalah Azotobacter chroococum, Bacillus subtilis, Bacillus licheniformis, dan Streptomyces sp. Penentuan waktu dan frekuensi aplikasi pupuk hayati yang tepat diharapkan dapat menurunkan penggunaan pupuk anorganik tetapi tetap mempertahankan kualitas, densitas, dan keseragaman rumput golf. Pupuk hayati juga diharapkan dapat menurunkan biaya perawatan dan mengatasi permasalahan pencemaran lingkungan dan perairan. Penelitian bertujuan untuk mempelajari pengaruh waktu awal dan frekuensi aplikasi pupuk hayati terhadap kualitas visual dan fungsional turfgrass.

Yusak, Dwi Guntoro, dan Achmad Zakaria

\section{BAHAN DAN METODE}

Penelitian dilaksanakan di lapangan golf Rainbow Hill and Country Club pada bulan Februari 2012 sampai dengan Agustus 2012. Lokasi penelitian terletak pada ketinggian 612 mdpl. Bahan yang digunakan pada penelitian adalah bahan tanam rumput Bermuda Cynodon dactylon (L.) var. Tifdwarft, pupuk hayati dengan merk dagang BIOPlantor, NPK (16-16-16), furadan, decis $2.5 \mathrm{EC}$. Alat yang digunakan dalam penelitian berupa saringan tanah, gembor, cangkul, kuadran $10 \mathrm{~cm}$ x $10 \mathrm{~cm}$, MCCP (Munsell Color Chart for Plant), timbangan, kuadran, penggaris, karung beras, gunting, amplop, oven, kored, kantung plastik, tali rafia, rol meteran, knapsack sprayer, neraca analitik.

Percobaan menggunakan Rancangan Petak Terbagi dalam Rancangan Kelompok Lengkap Teracak (RKLT) dengan dua faktor yaitu waktu awal aplikasi dan frekuensi aplikasi pupuk hayati dengan empat ulangan. Waktu awal aplikasi sebagai petak utama terdiri atas empat taraf, yaitu 1 minggu sebelum tanam (A1), 2 minggu sebelum tanam (A2), 3 minggu sebelum tanam (A3), dan 4 minggu sebelum tanam (A4). Frekuensi aplikasi pupuk hayati sebagai anak petak terdiri atas empat taraf, yaitu frekuensi 1 minggu sekali (F1), 2 minggu sekali (F2), 3 minggu sekali (F3), dan 4 minggu sekali (F4). Penelitian menggunakan 4 ulangan, sehingga terdapat 64 satuan percobaan. Data hasil penelitian dianalisis dengan analisi sidik ragam. Apabila hasil analisis menunjukkan pengaruh nyata maka dilakukan uji lanjut dengan Duncan's Multiple Range Test (DMRT) pada taraf 5\% (Gomez, 1995).

Penyiapan bahan tanam turfgrass dengan standar $1 \mathrm{~m}^{2}$ indukan digunakan untuk menanami 8 $\mathrm{m}^{2}$ lahan. Bahan tanam menggunakan sprig yaitu bahan tanam berupa pecahan rumpun yang terdiri atas akar batang dan daun lengkap tanpa tanah. Sprig disebar dengan persentase kerapatan 15\% kemudian ditutup tanah dengan ketebalan $1 \mathrm{~cm}$. Pupuk hayati BIOPlantor disiapkan dalam bentuk biakan. Dosis aplikasi yang digunakan adalah 11 per ha dengan volume semprot 2001 per ha. Pembiakan dilakukan dengan mencampurkan $10 \mathrm{ml}$ pupuk hayati dengan $40 \mathrm{~g}$ gula pasir dalam 1 liter air. Kemudian dilakukan inkubasi selama 3 hari. Petak percobaan dibuat di atas lahan yang sudah digemburkan dengan ukuran $1 \mathrm{~m}$ x $1 \mathrm{~m}$. Jarak antar anak petak $20 \mathrm{~cm}$ dan jarak antar ulangan $30 \mathrm{~cm}$. Aplikasi pupuk hayati dilakukan menggunakan 
Knapshack Sprayer High Volume (400 1 ha $^{-1}$ ) dengan nozel kuning (lebar semprot $1 \mathrm{~m}$ ).

Selama proses adaptasi dilakukan penyiraman dua kali sehari pada minggu pertama dan sekali sehari pada minggu kedua untuk memastikan bahan tanam tetap hidup. Kapasitas air untuk penyiraman rata-rata 3 liter per $\mathrm{m}^{2}$. Pemeliharaan meliputi penyiangan gulma, pengendalian hama dan penyakit, penyiraman, pemupukan, dan pemangkasan. Penyiangan gulma dilakukan setiap hari secara manual dengan mencabut gulma sampai ke akarnya. Pemupukan menggunakan dosis rekomendasi $5 \mathrm{~g} \mathrm{~N}+5 \mathrm{~g} \mathrm{P}_{2} \mathrm{O}_{5}$ $+5 \mathrm{~g} \mathrm{~K}_{2} \mathrm{O}$ per $\mathrm{m}^{2}$ per 2 minggu. Pemangkasan dilakukan setiap minggu untuk meningkatkan kepadatan pucuk rumput golf dan membuat pertumbuhannya seragam. Pengendalian hama dan penyakit dilakukan dengan cara aplikasi decis 2.5 ec dengan konsentrasi $1 \mathrm{ml} \mathrm{l}^{-1}$ dan mencabut rumput yang terserang penyakit tersebut.

Pengamatan yang dilakukan meliputi pengamatan kualitas visual dan kualitas fungsional. Pengamatan kualitas visual meliputi kepadatan pucuk, tekstur daun, dan warna daun. Pengamatan fungsional meliputi persentase penutupan tajuk, biomassa hasil pangkasan, panjang daun, diameter stolon, panjang akar, berat kering akar, dan daya recovery.

\section{HASIL DAN PEMBAHASAN}

\section{Keadaan Umum}

Keadaan iklim selama penelitian menunjukkan rata-rata curah hujan sedang sebesar $399 \mathrm{~mm} /$ bulan, kelembaban udara sebesar $81.4 \%$, kisaran suhu $25-30^{\circ} \mathrm{C}$ dan rata-rata 15 hari hujan/bulan (Stasiun Klimatologi Lapangan Golf Bukit Pelangi, Cijayanti, Kabupaten Bogor). Tanah tempat penelitian memiliki pH 5.3 dengan tekstur tanah pasir $30 \%$, debu $48 \%$, liat $22 \%$ (loam), C organik $0.70 \%, \mathrm{C} / \mathrm{N}$ rasio 10 , dan mengandung hara $\mathrm{N} 0.07 \%, \mathrm{P}_{2} \mathrm{O}_{5} 0.028 \%$ serta $\mathrm{K}_{2} \mathrm{O} 0.014 \%$. Kedalaman perakaran rumput golf di lokasi penelitian adalah $10 \mathrm{~cm}$ dengan densitas tanah liat $2 \mathrm{~g} / \mathrm{cm}^{3}$. Gulma yang terdapat pada awal penelitian adalah Digitaria adscendens, Polygala paniculata, dan Paspalum conjugatum. Gulma tersebut muncul secara spot. Pengendalian gulma ini dilakukan setiap hari secara manual, sehingga selama penelitian lahan selalu dalam kondisi bebas gulma. Selama penelitian terdapat serangan penyakit Bermudagrass white leaf dengan intensitas serangan kurang dari $1 \%$ di beberapa petak. Penyakit ini disebabkan oleh phytoplasma yang menyebar dari tanaman satu ke tanaman lain oleh vektor leafhopers, sejenis hama mirip wereng (Nilapharvata lugens). Pengendalian dilakukan dengan cara mencabut rumput yang terserang penyakit tersebut.

\section{Kualitas Visual Kepadatan Pucuk}

Frekuensi aplikasi satu minggu sekali dengan pemberian pupuk hayati empat minggu sebelum tanam merupakan kombinasi yang terbaik untuk meningkatkan kepadatan pucuk menjadi 195.2 pucuk. Menurut Beard (1973), rumput dikatakan berkualitas baik jika memiliki jumlah pucuk lebih dari 200 pucuk/100 $\mathrm{cm}^{2}$, berkualitas sedang jika jumlah pucuk 100-200 pucuk/100 $\mathrm{cm}^{2}$, dan berkualitas rendah jika kepadatannya kurang dari 100 pucuk/100 $\mathrm{cm}^{2}$ (Tabel 1). Cynodon dactylon (L.) var. Tifdwarft termasuk rumput katagori sedang. Berdasarkan studi literatur tersebut frekuensi aplikasi satu minggu sekali dengan pemberian pupuk hayati empat minggu sebelum tanam dapat meningkatkan kepadatan pucuk turfgrass. Hasil tersebut sejalan dengan penelitian Guntoro et al. (2006) bahwa pemberian pupuk hayati mikoriza 50\% Dosis Rekomendasi mampu meningkatkan kepadatan pucuk Cynodon dactylon (L.) var. Tifdwarft sebesar $79.5 \%$.

Kombinasi waktu awal aplikasi empat minggu sebelum tanam dengan frekuensi aplikasi dua minggu sekali merupakan kombinasi terbaik untuk meningkatkan lebar daun menjadi $1.48 \mathrm{~mm}$ (Tabel 1). Berdasarkan katagori Beard (1973) lebar daun yang dihasilkan termasuk dalam katagori halus (1-2 mm). Menurut Turgeon (2004) lebar daun mengindikasikan suatu rumput memiliki tekstur yang halus atau kasar. Emmons (2000) menyatakan bahwa semakin sempit lebar daun, maka tekstur rumput tersebut semakin halus secara visual dan memberikan penampilan yang menarik. Hasil penelitian ini sejalan dengan Guntoro et al. (2007) bahwa pemberian pupuk hayati mikoriza dapat meningkatkan lebar daun rumput golf. Lebar daun rumput berkisar antara $1.53 \mathrm{~mm}$ sampai dengan $1.23 \mathrm{~mm}$. Kombinasi frekuensi aplikasi dua minggu sekali dengan waktu aplikasi awal tiga minggu sebelum tanam merupakan kombinasi terbaik untuk meningkatkan warna daun (Tabel 1). Hasil tersebut tidak sejalan dengan penelitian Guntoro et al. (2006) dan Guntoro et al. (2007) yang menyatakan pemberian pupuk hayati mikoriza 
tidak berpengaruh nyata terhadap warna daun rumput golf. Wijaya (2013) menambahkan pemberian pupuk hayati tidak mempengaruhi warna daun. Hal ini diduga akibat tingginya intensitas radiasi di lahan penelitian. Menurut
Guntoro et al. (2006) intensitas radiasi di luar green house mencapai $0.6 \mathrm{cal}$ per $\mathrm{cm}^{2}$ per menit ${ }^{-1}$. Diduga tingginya intensitas radiasi memacu reaksi fotosintesis yang diikuti dengan peningkatan warna daun.

Tabel 1. Interaksi waktu awal dengan frekuensi aplikasi pupuk hayati terhadap kepadatan pucuk, lebar daun, dan warna daun

\begin{tabular}{|c|c|c|c|c|}
\hline Perlakuan & \multicolumn{4}{|c|}{ Frekuensi aplikasi } \\
\hline Waktu aplikasi & F1 & F2 & F3 & $\mathrm{F}_{2}$ \\
\hline & \multicolumn{4}{|c|}{$\begin{array}{l}\text { Kepadatan pucuk* } \\
\ldots\left(\text { pucuk } / 100 \mathrm{~cm}^{2}\right) \ldots \ldots\end{array}$} \\
\hline $1 \mathrm{MSbT}$ & $154.2 b$ & $129.5 \mathrm{bcd}$ & $104.5 \mathrm{c}-\mathrm{f}$ & $77.8 \mathrm{f}$ \\
\hline $2 \mathrm{MSbT}$ & $187.8 \mathrm{a}$ & $138.2 \mathrm{bc}$ & 93.2ef & $92.5 \mathrm{ef}$ \\
\hline $3 \mathrm{MSbT}$ & $146.2 b$ & $154.2 \mathrm{~b}$ & 111.0cdef & 96.0def \\
\hline \multirow[t]{2}{*}{$4 \mathrm{MSbT}$} & $195.2 \mathrm{a}$ & $119.8 b-e$ & $119.2 b-e$ & $89.5 \mathrm{ef}$ \\
\hline & \multicolumn{4}{|c|}{ Lebar daun^ } \\
\hline $1 \mathrm{MSbT}$ & $1.49 \mathrm{a}$ & $1.51 \mathrm{a}$ & $1.51 \mathrm{a}$ & $1.51 \mathrm{a}$ \\
\hline $2 \mathrm{MSbT}$ & $1.49 \mathrm{a}$ & $1.50 \mathrm{a}$ & $1.33 b c$ & $1.23 \mathrm{~d}$ \\
\hline $3 \mathrm{MSbT}$ & $1.53 \mathrm{a}$ & $1.46 \mathrm{a}$ & $1.35 \mathrm{~b}$ & $1.24 \mathrm{~cd}$ \\
\hline \multirow[t]{2}{*}{$4 \mathrm{MSbT}$} & $1.46 \mathrm{a}$ & $1.48 \mathrm{a}$ & $1.36 \mathrm{~b}$ & $1.25 \mathrm{~cd}$ \\
\hline & \multicolumn{4}{|c|}{ Warna daun ${ }^{\#}$} \\
\hline $1 \mathrm{MSbT}$ & $5.2 \mathrm{a}$ & $5.2 \mathrm{a}$ & $4.6 \mathrm{bc}$ & $4.3 \mathrm{cde}$ \\
\hline $2 \mathrm{MSbT}$ & $5.5 \mathrm{a}$ & $5.2 \mathrm{a}$ & $4.3 \mathrm{cde}$ & 4.0de \\
\hline $3 \mathrm{MSbT}$ & $5.2 \mathrm{a}$ & $5.5 \mathrm{a}$ & $4.3 \mathrm{cde}$ & 4.0de \\
\hline $4 \mathrm{MSbT}$ & $5.1 \mathrm{ab}$ & $4.5 \mathrm{~cd}$ & $4.0 \mathrm{e}$ & $4.1 \mathrm{cde}$ \\
\hline
\end{tabular}

\section{Kualitas Fungsional}

Tabel 2. Interaksi waktu awal dengan frekuensi aplikasi terhadap persentase penutupan tajuk

\begin{tabular}{lcccc}
\hline \multicolumn{1}{c}{ Perlakuan } & \multicolumn{3}{c}{ Frekuensi aplikasi } \\
\hline \multicolumn{1}{c}{ Waktu aplikasi } & F1 & F2 & F3 \\
& & & $\ldots \ldots \ldots \ldots(\%) \ldots \ldots \ldots \ldots$ & \\
$1 \mathrm{MSbT}$ & $100.0 \mathrm{a}$ & $100.0 \mathrm{a}$ & $8 \mathrm{MST}$ & $88.5 \mathrm{~d}$ \\
$2 \mathrm{MSbT}$ & $100.0 \mathrm{a}$ & $99.1 \mathrm{a}$ & $97.3 \mathrm{~b}$ & $93.7 \mathrm{c}$ \\
$3 \mathrm{MSbT}$ & $100.0 \mathrm{a}$ & $99.7 \mathrm{a}$ & $97.9 \mathrm{ab}$ & $93.3 \mathrm{c}$ \\
$4 \mathrm{MSbT}$ & $99.7 \mathrm{a}$ & $97.8 \mathrm{a}$ & $98.1 \mathrm{bc}$ & $85.3 \mathrm{e}$ \\
\hline & & & $98.5 \mathrm{~d}$ & \\
$1 \mathrm{MSbT}$ & $100.0 \mathrm{a}$ & $100.0 \mathrm{a}$ & $99.4 \mathrm{a}$ & $97.7 \mathrm{~b}$ \\
$2 \mathrm{MSbT}$ & $100.0 \mathrm{a}$ & $100.0 \mathrm{a}$ & $100.0 \mathrm{a}$ & $98.7 \mathrm{ab}$ \\
$3 \mathrm{MSbT}$ & $100.0 \mathrm{a}$ & $100.0 \mathrm{a}$ & $97.7 \mathrm{~b}$ & $97.8 \mathrm{~b}$ \\
$4 \mathrm{MSbT}$ & $100.0 \mathrm{a}$ & $100.0 \mathrm{a}$ & $95.3 \mathrm{c}$ & $94.8 \mathrm{c}$ \\
\hline
\end{tabular}

Keterangan : Angka yang diikuti huruf yang sama pada kolom dan baris yang sama pada tiap faktor tidak berbeda nyata pada uji lanjut DMRT taraf 5\%, MSbT= minggu sebelum tanam, F1= 1 Minggu sekali, F2= 2 Minggu sekali, F3= 3 Minggu sekali, F4= 4 Minggu sekali 
Berdasarkan analisis ragam terdapat interaksi sangat nyata antara waktu awal aplikasi dan frekuensi aplikasi terhadap persentase penutupan tajuk pada 8 MST dan 9 MST. Pada 8 MST frekuensi aplikasi 2 minggu sekali menunjukkan persentase penutupan tajuk yang tidak berbeda nyata dibandingkan frekuensi aplikasi 1 minggu sekali. Pada semua waktu awal aplikasi, frekuensi aplikasi 4 minggu sekali menunjukkan persentase penutupan tajuk yang berbeda nyata dibandingkan frekuensi aplikasi 1, 2, dan 3 minggu sekali. Pada 9 MST frekuensi aplikasi 2 minggu sekali tidak menunjukkan perbedaan nyata terhadap frekuensi aplikasi 1 minggu sekali. Kombinasi waktu awal aplikasi 2 minggu sebelum tanam dengan frekuensi aplikasi 3 minggu sekali dapat meningkatkan penutupan tajuk (Tabel 2). Hasil tersebut sejalan dengan penelitian Wijaya (2013) bahwa aplikasi pupuk hayati dapat meningkatkan penutupan tajuk. Hasil ini juga sejalan dengan penelitian sebelumnya bahwa pemberian pupuk hayati dapat meningkatkan biomassa tajuk (Wijaya, 2013).

Interaksi antara waktu awal aplikasi dengan frekuensi aplikasi pupuk hayati terhadap biomassa pucuk terjadi pada 12 MST dan 13 MST. Waktu awal aplikasi 1 minggu sebelum tanam pada 12
MST menunjukkan biomassa pangkasan yang berbeda nyata pada semua frekuensi aplikasi. Kombinasi waktu awal aplikasi 2 minggu sebelum tanam dengan frekuensi aplikasi 1 minggu sekali menunjukkan biomassa terbaik dibandingkan kombinasi lainnya (Tabel 3). Kombinasi waktu awal aplikasi 2 dan 4 minggu sebelum tanam dengan frekuensi aplikasi 1 minggu sekali pada 13 MST menunjukkan biomassa pucuk yang paling besar $(5.2 \mathrm{~g}$ dan $5.4 \mathrm{~g})$ dibandingkan kombinasi waktu dan frekuensi lainnya. Biomassa pucuk terkecil ditunjukkan oleh waktu awal aplikasi 1 minggu sebelum tanam dengan frekuensi aplikasi 4 minggu sekali yaitu $2.1 \mathrm{~g}$ (Tabel 3). Menurut Guntoro et al. (2006) inokulasi CMA pada dosis pupuk 25\% Dosis Rekomendasi mampu meningkatkan kandungan $\mathrm{N}$ tajuk, serapan $\mathrm{N}$ tajuk, dan efisiensi pemupukan $\mathrm{N}$ masing-masing sebesar $226.2 \%, 193.4 \%$, dan $106.9 \%$ dibandingkan dengan kontrol. Semakin tinggi kandungan $\mathrm{N}$ dalam tanah menyebabkan sintesis sitokinin semakin tinggi. Semakin tinggi sitokinin semakin banyak kuncup lateral yang terbentuk maka peningkatan tajuk akan semakin cepat. Peningkatan penutupan tajuk ditandai peningkatan jumlah pucuk sehingga akan berimplikasi pada peningkatan biomassa pangkasan.

Tabel 3. Interaksi antara waktu awal dan frekuensi aplikasi pupuk hayati terhadap biomassa pucuk

\begin{tabular}{|c|c|c|c|c|c|}
\hline Perlakuan & \multicolumn{5}{|c|}{ Frekuensi aplikasi } \\
\hline Waktu aplikasi & \multirow{2}{*}{\multicolumn{5}{|c|}{..$\left(\mathrm{g} / 100 \mathrm{~cm}^{2}\right)}}$. \\
\hline & \multicolumn{3}{|c|}{$12 \mathrm{MST}$} & & \\
\hline $1 \mathrm{MSbT}$ & $4.1 \mathrm{a}$ & & $3.1 b c$ & $2.2 \mathrm{efg}$ & $1.6 \mathrm{j}$ \\
\hline $2 \mathrm{MSbT}$ & $3.9 \mathrm{a}$ & & $2.6 \mathrm{de}$ & $2.0 \mathrm{f}-\mathrm{i}$ & $2.0 f-j$ \\
\hline $3 \mathrm{MSbT}$ & $3.4 \mathrm{~b}$ & & $2.4 \mathrm{def}$ & $1.9 \mathrm{f}-\mathrm{j}$ & $1.8 \mathrm{hij}$ \\
\hline $4 \mathrm{MSbT}$ & $2.8 \mathrm{~cd}$ & & $2.2 \mathrm{e}-\mathrm{h}$ & $1.8 \mathrm{ij}$ & $1.9 \mathrm{~g}-\mathrm{j}$ \\
\hline & \multicolumn{5}{|c|}{$13 \mathrm{MST}$} \\
\hline $1 \mathrm{MSbT}$ & $4.2 \mathrm{~b}$ & & $3.6 \mathrm{~b}-\mathrm{e}$ & $2.9 \mathrm{efg}$ & $2.1 \mathrm{~g}$ \\
\hline $2 \mathrm{MSbT}$ & $5.2 \mathrm{a}$ & & $3.8 \mathrm{bcd}$ & $2.6 \mathrm{fg}$ & $2.5 \mathrm{fg}$ \\
\hline $3 \mathrm{MSbT}$ & $4.0 \mathrm{bc}$ & & $4.2 \mathrm{~b}$ & $3.1 \mathrm{~d}-\mathrm{g}$ & 2.6efg \\
\hline $4 \mathrm{MSbT}$ & $5.4 \mathrm{a}$ & & $3.3 \mathrm{c}-\mathrm{f}$ & $3.3 \mathrm{c}-\mathrm{f}$ & $2.4 \mathrm{fg}$ \\
\hline
\end{tabular}

Keterangan : Angka yang diikuti huruf yang sama pada kolom dan baris yang sama pada tiap faktor tidak berbeda nyata pada uji lanjut DMRT taraf 5\%, MSbT= minggu sebelum tanam, F1= 1 Minggu sekali, F2=2 Minggu sekali, F3= 3 Minggu sekali, F4= 4 Minggu sekali.

Interaksi antara waktu awal aplikasi dengan frekuensi aplikasi mempengaruhi panjang daun dan diameter stolon pada 14 MST. Kombinasi waktu awal aplikasi 3 minggu sebelum tanam dengan frekuensi aplikasi 2 minggu sekali meningkatkan panjang daun menjadi $28.92 \mathrm{~mm}$ (Tabel 4). Peningkatan jumlah pucuk diduga dapat meningkatkan persaingan mendapatkan faktor tumbuh berupa cahaya. Cahaya yang terbatas memicu terjadinya etiolasi. Kompetisi intraspesies membuat pertumbuhan fokus mendapatkan cahaya dengan cara memperpanjang ruas, memperkecil diameter stolon, dan memperpanjang daun. 
Tabel 4. Interaksi antara waktu aplikasi dengan frekuensi aplikasi terhadap panjang daun dan diameter stolon pada 14 MST

\begin{tabular}{|c|c|c|c|c|}
\hline Perlakuan & \multicolumn{4}{|c|}{ Frekuensi aplikasi } \\
\hline Waktu aplikasi & $\mathrm{F} 1$ & $\mathrm{~F} 2$ & F3 & $\mathrm{F} 4$ \\
\hline & \multicolumn{4}{|c|}{$\begin{array}{l}\text {........(mm) ........... } \\
\text { Panjang daun }\end{array}$} \\
\hline $1 \mathrm{MSbT}$ & $29.69 \mathrm{a}$ & $28.31 \mathrm{abc}$ & $24.94 \mathrm{ef}$ & $23.73 \mathrm{f}$ \\
\hline $2 \mathrm{MSbT}$ & $28.13 \mathrm{abc}$ & 25.60de & $23.73 \mathrm{f}$ & $23.50 \mathrm{f}$ \\
\hline $3 \mathrm{MSbT}$ & $26.77 \mathrm{~cd}$ & $28.92 \mathrm{ab}$ & $23.89 \mathrm{f}$ & $23.37 \mathrm{f}$ \\
\hline $4 \mathrm{MSbT}$ & $27.75 b c$ & $26.74 \mathrm{~cd}$ & $23.84 \mathrm{f}$ & $24.71 \mathrm{ef}$ \\
\hline & \multicolumn{4}{|c|}{ Diameter stolon } \\
\hline $1 \mathrm{MSbT}$ & $0.78 \mathrm{def}$ & $0.76 f$ & $0.85 \mathrm{ab}$ & $0.80 \mathrm{c}-\mathrm{f}$ \\
\hline $2 \mathrm{MSbT}$ & $0.79 \mathrm{def}$ & $0.81 \mathrm{bcd}$ & $0.83 \mathrm{bcd}$ & $0.87 \mathrm{a}$ \\
\hline $3 \mathrm{MSbT}$ & $0.80 \mathrm{c}-\mathrm{f}$ & $0.81 \mathrm{~b}-\mathrm{e}$ & $0.82 \mathrm{bcd}$ & $0.87 \mathrm{a}$ \\
\hline $4 \mathrm{MSbT}$ & $0.79 \mathrm{def}$ & $0.77 \mathrm{ef}$ & $0.84 a b c$ & $0.87 \mathrm{a}$ \\
\hline
\end{tabular}

Keterangan : Angka yang diikuti huruf yang sama pada kolom dan baris yang sama pada tiap faktor tidak berbeda nyata pada uji lanjut DMRT taraf 5\%, MSbT= minggu sebelum tanam, F1= 1 Minggu sekali, F2= 2 Minggu sekali, F3= 3 Minggu sekali, F4= 4 Minggu sekali.

Daya recovery, panjang akar, dan biomassa akar dipengaruhi oleh faktor tunggal antara waktu awal aplikasi dan frekuensi aplikasi. Waktu awal aplikasi 3 minggu sebelum tanam dapat mempercepat waktu recovery dibandingkan dengan waktu awal aplikasi 4 minggu sebelum tanam. Frekuensi aplikasi 1 minggu sekali menunjukkan waktu recovery paling baik dan dapat mempercepat recovery 6 hari dibandingkan frekuensi aplikasi 4 minggu sekali. Waktu awal aplikasi 1 minggu sebelum tanam dapat meningkatkan panjang akar menjadi $13.11 \mathrm{~cm}$. Frekuensi aplikasi 1 minggu sekali menunjukkan panjang akar terbaik dan meningkatkan panjang akar menjadi $15.85 \mathrm{~cm}$. Waktu awal aplikasi 1 minggu sebelum tanam dapat meningkatkan biomassa akar menjadi 1.83 gram dan berbeda nyata dengan waktu awal aplikasi 2, 3, dan 4 minggu sebelum tanam. Frekuensi aplikasi 1 minggu sekali memiliki biomassa akar terbaik yaitu 2.14 gram sedangkan frekuensi aplikasi 4 minggu sekali menurunkan biomassa akar menjadi 1.18 gram (Tabel 5). Menurut Sulistiani (2009) formulasi spora Bacillus subtilis efektif dalam memacu pertumbuhan akar dan tajuk pada benih padi. Hasil ini sejalan dengan penelitian Wijaya (2013) bahwa aplikasi pupuk hayati yang mengandung mikoriza mampu meningkatkan panjang akar dan biomassa akar rumput golf.

Tabel 5. Pengaruh faktor tunggal antara waktu awal dan frekuensi aplikasi

\begin{tabular}{lccc}
\hline \multicolumn{1}{c}{ Perlakuan } & Daya Wecovery (hari) & Panjang akar $(\mathrm{cm})$ & Biomassa akar $\left(\mathrm{g} / 78.5 \mathrm{~cm}^{2}\right)$ \\
\hline 1 MSbT & $11.9 \mathrm{~b}$ & $13.11 \mathrm{a}$ & $1.83 \mathrm{a}$ \\
$2 \mathrm{MSbT}$ & $12.2 \mathrm{~b}$ & $12.18 \mathrm{~b}$ & $1.68 \mathrm{~b}$ \\
$3 \mathrm{MSbT}$ & $11.9 \mathrm{~b}$ & $11.87 \mathrm{~b}$ & $1.60 \mathrm{~b}$ \\
4 MSbT & $13.2 \mathrm{a}$ & $11.62 \mathrm{~b}$ & $1.46 \mathrm{c}$ \\
\hline Frekuensi & & & $2.14 \mathrm{a}$ \\
\hline minggu & $9.9 \mathrm{~d}$ & $15.85 \mathrm{a}$ & $1.88 \mathrm{~b}$ \\
2 minggu & $10.6 \mathrm{c}$ & $13.91 \mathrm{~b}$ & $1.39 \mathrm{c}$ \\
3 minggu & $13.6 \mathrm{~b}$ & $10.26 \mathrm{c}$ & $1.18 \mathrm{~d}$ \\
\hline minggu & $15.2 \mathrm{a}$ & $8.76 \mathrm{c}$ & \\
\hline
\end{tabular}

Keterangan : Angka yang diikuti huruf yang sama pada kolom dan baris yang sama pada tiap faktor tidak berbeda nyata pada uji lanjut DMRT taraf $5 \%$, MSbT $=$ minggu sebelum tanam 


\section{KESIMPULAN}

Frekuensi aplikasi satu minggu sekali menunjukkan kualitas visual dan fungsional terbaik dan tidak berbeda nyata dibandingkan frekuensi aplikasi dua minggu sekali. Waktu awal aplikasi tiga minggu sebelum tanam dan frekuensi aplikasi dua minggu sekali merupakan perlakuan terbaik untuk mempertahankan kualitas visual dan fungsional turfgrass, yaitu meningkatkan kepadatan pucuk, lebar daun, warna daun, panjang daun, biomassa pangkasan, persentase penutupan tajuk, meningkatkan panjang akar, biomassa akar, mempercepat waktu recovery, dan menurunkan diameter stolon.

Aplikasi pupuk hayati tiga minggu sebelum tanam dikombinasikan dengan frekuensi aplikasi dua minggu sekali mampu menghemat $50 \%$ biaya pengeluaran maintenance green dan tee box. Penggunaan pupuk hayati dalam jangka panjang dapat mengurangi kandungan thatch dan mat di daerah green dan tee box.

\section{DAFTAR PUSTAKA}

Beard, J.B. 1973. Turfgrass Science and Culture. New Jersey (US): Prentice Hall, Inc. Englewood Cliffs.

Emmons, R.D. 2000. Turfgrass Science and Management. $3^{\text {rd }}$ ed. Columbia (US): Delmar.

Gomez, K.A., Gomez, A.A. 1995. Prosedur Statistik untuk Penelitian Pertanian. Sjamsudin E dan Baharsjah JS, penerjemah. Jakarta (ID): UI Pr. Terjemahan dari: Statistical Procedures for Agricultural Research.
Guntoro, D., Chozin, M.A., Tjahjono, B., Mansur, I. 2006. Pemanfaatan cendawan mikoriza arbuskula dan bakteri Azospirillum sp. untuk meningkatkan efisiensi pemupukan pada turfgrass. J Agron Indonesia. 34(1):62-70.

Guntoro, D., Purwoko, B.S., Hurriyah, R.G. 2007. Pertumbuhan, serapan hara dan kualitas turfgrass pada beberapa dosis pemberian pupuk hayati mikoriza. J Agron Indonesia. 35(2): $142-147$.

[Permentan]. 2009. Peraturan Menteri Pertanian Republik Indonesia tentang pupuk organik, pupuk hayati, dan pupuk pembenah tanah No. 28/Permentan/SR.130/5/2009.

Desember 2013].

Schaan, C.M, Devitt, D.A., Morris, R.L., Clarck, L. 2003. Cyclic irrigation of turfgrass using a shallow saline aquifer. J Agron. 95: 660-667.

Sulistiani. 2009. Formulasi spora Bacillus subtilis sebagai agens hayati dan PGPR (Plant Growth Promoting Rhizobacteria) pada berbagai bahan pembawa. [skripsi]. Bogor (ID): Institut Pertanian Bogor.

Turgeon, A.J. 2004. Turfgrass Management. $7^{\text {th }}$ ed. New Jersey (US): Prentice Hall, Inc. Englewood Cliffs.

Wijaya, D.N. 2013. Efisiensi Hara pada Rumput Golf dengann Pemberian Pupuk Hayati [Skripsi]. Bogor (ID) Institut Pertanian Bogor. 